\title{
Computationally approached inhibition potential of Tinospora Cordifolia towards COVID-19 targets
}

\section{Sushovan Jena}

Vellore Institute of Technology, Vellore

\section{Punnagai Munusami}

Arignar Anna Government Arts \& Science College

Balamurali MM ( $\triangle$ mmbala@gmail.com )

Vellore Institute of Technology,

Kaushik Chanda ( $\nabla$ chandakaushik1@gmail.com )

Vellore Institute of Technology, Vellore https://orcid.org/0000-0002-7555-9322

\section{Research Article}

Keywords: SARS-COV-2, Natural Product, Computational chemistry, Virus

Posted Date: November 6th, 2020

DOl: https://doi.org/10.21203/rs.3.rs-103345/v1

License: (c) (1) This work is licensed under a Creative Commons Attribution 4.0 International License.

Read Full License

Version of Record: A version of this preprint was published at VirusDisease on March 1st, 2021. See the published version at https://doi.org/10.1007/s13337-021-00666-7. 


\title{
Computationally approached inhibition potential of Tinospora Cordifolia towards COVID-19 targets
}

\author{
Sushovan Jena, ${ }^{\text {a }}$ Punnagai Munusami ${ }^{\mathrm{b}}$, Balamurali $\mathrm{MM}^{* \mathrm{c}}$ and Kaushik Chanda*a \\ ${ }^{a}$ Department of Chemistry, School of Advanced Sciences, Vellore Institute of Technology, \\ Vellore, India. \\ ${ }^{b}$ Department of Chemistry, Arignar Anna Government Arts \& Science College, Karaikal - \\ 609605, Puducherry (U.T), India \\ ${ }^{c}$ Division of Chemistry, School of Advanced Sciences, Vellore Institute of Technology, \\ Chennai campus, Chennai, India
}

\section{Email: chandakaushik1@gmail.com \\ $\underline{\text { mmbala@gmaill.com }}$}

\begin{abstract}
The recent emergence of novel coronavirus (SARS-CoV-2) has been a major threat to human society, as the challenge of finding a suitable drug or vaccine is not met till date. With increasing morbidity and mortality, the need for novel drug candidates is under great demand. The investigations are progressing towards COVID-19 therapeutics and among the various strategies employed, the use of repurposed drugs is competing along with novel drug inventions [1]. Based on the therapeutic significance, the chemical constituents from the extract of Tinospora Cordifolia belonging to various classes like alkaloids, lignans, steroids and terpenoids will be investigated as potential drug candidates for COVID-19. The inhibition potential of the proposed compounds against viral spike protein and human receptor ACE2 were evaluated by computational molecular modeling (Auto dock), along with their ADME/T properties. Prior to docking, the initial geometry of the compounds were optimized by Density functional theory (DFT) method employing B3LYP hybrid functional and $6-311++\mathrm{G}(\mathrm{d}, \mathrm{p})$ basis set. The results of molecular docking and ADME/T studies have revealed 6 constituents as potential drug candidates that can inhibit the binding of SARSCoV-2 spike protein with the human receptor ACE2 protein. The narrowed down list of constituents from Tinospora Cordifolia have paved way for further tuning their ability to
\end{abstract}


inhibit COVID-19 by modifying the chemical structures and by employing computational geometry optimization and docking methods.

\section{Graphical abstract}

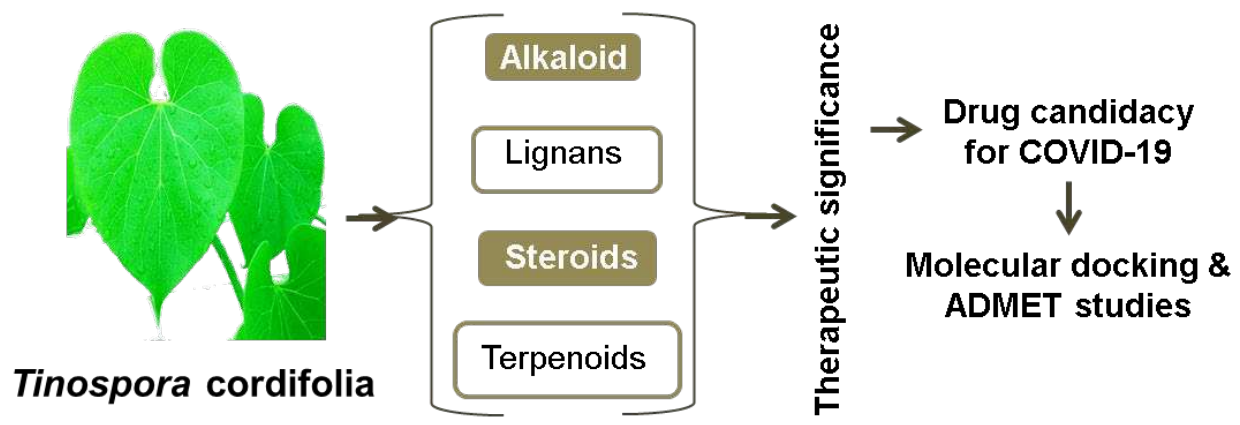




\section{Introduction}

The emergence of COVID-19 pandemic [2, 3] in December 2019, caused by the second version of Corona virus $[4,5]$ has imposed severe social and economic burden in countries across the globe. This viral infection induces severe acute respiratory syndrome (SARS) in humans, though no evidence in animals has been reported [6]. The disease is believed that the viral spread is not air / water borne or through insects / animals. It has spread to many countries round the globe mainly through societal interactions including transmission from human-to-human through droplets, contaminated hand or surface contacts. Now there has been a daunting task for the scientists to not only control the morbidity but also the steeply raising mortality [7].

Though the mode of infection by SARS-CoV-2 is known to be very similar to SARS-CoV [8, 9], there exists the challenge of controlling the rate of infection and rapid treatment methods to the infected patients $[10,11]$. Till date no antiviral drugs with proven efficacy nor are there vaccines for its prevention. Several clinically available antiviral drugs are reported in the literature and have been in use to suppress different viral particles $[12,13]$. For the past $10-15$ years, researchers are working on the development of antiviral drugs for SARS-CoV and MERS-CoV $[14,15]$ and till date no successful results appear. Now SARS-CoV-2 joins this list.

The present focus of investigations resides on two targets: 1. Virus (Receptor binding motifs spike (S), envelope (E) and nucleocapsid (N) proteins, RNA dependent RNA polymerases and 2. Receptor motif on human ACE2 (angiotensin converting enzyme) and its associated functional proteins like TMPRSS2 and $\mathrm{B}^{0} \mathrm{AT} 1$. It is difficult to have a complete evaluation of small molecular drug candidates for therapies directed towards the host with the inadequately available knowledge on the molecular details of the infection caused by SARS-CoV2 $[16,17]$. Recently, several research works have been published with novel and refurbished drug candidates to tackle the situation [13]. 
Until recently, there was a speculation that hydroxychloroquine (HCQS) could inhibit the viral infection [18]. But there was no solid proof on the method of inhibition. With the current status on the spread of infection, it is mandatory on emergency basis to develop strategies to control the morbidity and mortality. A systematic understanding on the host dependencies of the SARS-CoV-2 virus to identify other host proteins is the need of the hour. Many therapeutic strategies target the host-virus interface, but such drugs are prone to induced severe side effects [18]. It is very unfortunate that we have very minimal knowledge on the molecular details of SARS-CoV-2 infection to further proceed with a comprehensive evaluation of small molecular therapeutic candidates directed towards the host. Several mathematical models $[19,20]$ and computational strategies [21] are being currently under investigation to identify the interactions at the interface. Moreover, to devise therapeutic strategies, it is important to know how the virus invades the humans during infection and this knowledge can be applied to develop new drugs and to repurpose the existing ones [22]. There are also reports on the various constituents from plants [23] of medicinal values as potential inhibitors and anti-viral drugs [24-26].

Recently, Government of India has released an advisory from the ministry of Ayurveda, to meet the challenges caused by the rapid spread of COVID-19 in India [27]. The major focus of this system was to bring lifestyle modifications and prophylactics to improve the immunity in humans. In this context, it was reported that an ayurvedic medicine Samshamani Vati (aqueous extract of Tinospora cordifolia), when administered at $500 \mathrm{mg}$, twice a day for 15 days, could serve as prophylaxis. The same is also reported to induce immunomodulatory effect [28-30] in human immuno-deficiency virus positive patients. [31] Tinospora cordifolia is known to exhibit a broad spectrum of therapeutic activities [32].

With the available scientific approaches and computational facilities to model proteins and investigate protein-ligand interactions it becomes more supportive to predict the binding of 
small molecular drugs to protein targets $[26,33,34]$. Employing density functional theory [35] the geometry of all the molecules proposed as COVID-19 drug candidates, were optimized to understand structural features and hence their contribution to the inhibition or druggable potential. In continuation of our efforts to explore the potential application of synthesized bioactive compounds in our laboratory [36-39], for the first time, herein we are reporting the inhibitory effects of selected constituents of Tinospora Cordifolia on human ACE2 protein and the main protease of SARS-CoV-2 using molecular docking and pharmacokinetic studies. In this manuscript, we have investigated the various constituents of Tinospora Cordifolia for their potency to inhibit the host receptor for SARS-CoV-2 by molecular docking interactions. Two different targets (ACE2 and Main protease) were chosen for the investigation.

\section{Materials and Methods}

\subsection{Docking Calculations}

The X-ray structure were obtained from Brookhaven Protein Data Bank for SARS coronavirus spike receptor-binding domain complexed with its receptor (PDB id: 2AJF) and the main protease of COVID-19 in complex with an inhibitor (PDB ID: 6LU7) and were considered for docking studies. The crystal structures were refined by removing the bound receptors, inhibitors, water molecules and other hetero atoms. Further, using AutoDockTools1.5.6, the Kollman charges [59] were assigned to the proteins after adding the hydrogen atoms. Employing molecular mechanics, the 3D coordinates of the proposed inhibitors were constructed and optimized. Auto Tors was used to define the possible torsions associated with the inhibitors. All the inhibitors were treated as flexible throughout the docking procedures. The already reported binding pocket in the proteins was used to generate a grid box to encapsulate the active site. The auto grid program was used to pre-calculate the grid maps of interaction energies between protein and various atom types present in the inhibitors. The 
conformational states of the flexible inhibitors were explored using Lamarckian genetic algorithm coupled with energy assessments based on AMBER force field. Docking calculations were performed with default parameters. The binding energy was evaluated using the following scoring function.

$$
\Delta G=\Delta G_{v d w}+\Delta G_{\text {hbond }}+\Delta G_{\text {elec }}+\Delta G_{\text {tor }}+\Delta G_{\text {desolv }}
$$

The free energy upon binding of the flexible ligand to the rigid target could be calculated using the equation that includes parameters like $\Delta \mathrm{G}_{\mathrm{vdw}}$ (dispersion/repulsion), $\Delta \mathrm{G}_{\mathrm{elec}}$ (electrostatic interaction), $\Delta \mathrm{G}_{\text {hbond }}$ (hydrogen bonding), $\Delta \mathrm{G}_{\text {tor }}$ (torsional constraints) and $\Delta \mathrm{G}_{\text {sol }}$ (desolvation effects).

\subsection{ADMET Predictions}

The pharmaco-kinetic properties such as absorption, distribution, metabolism, excretion and toxicity (ADMET) were predicted using the pkCSM/ADMET. [60, 61] This method employs graph-based signatures to develop predictive models for generating central ADMET properties for drug development. In absorption process, the drug reaches the blood stream from the site of the drug administration. The absorption of drugs depends on factors including polar surface area (PSA), membrane permeability (LogP), cell-based methods such as Caco2, intestinal absorption, skin permeability levels, P-glycoprotein substrate or inhibitor. This approach uses various parameters such as the blood-brain barrier $(\log B B)$, CNS permeability $(\log \mathrm{PB})$, and the volume of distribution (VDss) are evaluating the distribution of drugs. Using CYP models for substrate (CYP2D6, CYP1A2, CYP2C19, CYP2C9, and CYP3A4) the metabolisms of the drug molecules are evaluated. Excretion, a process where the body eliminates an unchanged drug or its metabolite, is predicted based on the total clearance model and renal OCT2 substrate. The toxicity of drugs is predicted based on AMES toxicity, hERG inhibition, hepatotoxicity, and skin sensitization. [62-63] The PSA value relates the 
absorption properties of the inhibitor drugs. The PSA value of compounds greater than 140 indicates that the compounds have strong polarity and were poorly absorbed. The lipophilicity values are predicted by the $\log \mathrm{P}$ value. The $\log \mathrm{P}$ values less than 5 shows that the compound can easily permeable into cell membrane. Apart from these two parameters PSA and $\log$ P, the following parameters such as Caco-2 permeability, intestinal absorption (human), skin permeability, and P-glycoprotein substrate or inhibitor were used to predict the absorption properties of the compounds. When the compounds exhibit the predicted value of $>0.90$ indicated that the compound has high Caco-2 permeability and easily absorbed. The intestinal absorption (human), less than $30 \%$ is considered as poor absorption. The $\operatorname{logKp}$ value of greater than -2.5 is considered as poor skin permeability. The permeability glycoprotein (P-glycoprotein) also known as multidrug resistant protein or ATP binding Cassette $(\mathrm{ABC})$ is an important protein in the cell membrane that eliminates the toxins and foreign substances from the cells. After the drug is absorbed from the membrane, the drug should be distributed to various tissues in the body to produce the pharmacological effects. The distribution volume (VDss) is a parameter which predicts the distribution of drugs in various tissues in the body. When the $\log$ VDss $<-0.15$ is considered as low distribution and higher than $>0.45$ is considered as high distribution. After the drug absorbed in the body, the circulating drug exist in either bound or unbound state with the serum proteins in the blood. The efficacy of the drug may be affected by the fraction of drug binds with proteins within blood; the more bound state leads to poor efficacy. The blood brain barriers (BBB) protect the brain from exogenous compounds and selectively transport various nutrients, ions and other molecules that are crucial for neural functions. The BBB parameter is the important factor which is measured in vivo in animal models as $\log B$. The $\log B B$ value greater than 0.3 shows that the compounds can easily cross the $\mathrm{BBB}$ and $\log \mathrm{BB}<-1$ suggest that the compounds can't easily cross the BBB. Compounds with $\log \mathrm{PB}>-2$ are considered to 
penetrate the CNS, and $\log \mathrm{PB}<-3$ are considered unable to penetrate the CNS. The central nervous system (CNS) permeability is obtained by direct measurement of blood-brain permeability-surface area product. The CNS permeability between -3 to -2 is considered as penetrable to CNS. Cytochrome P450s plays important role in drug metabolism. Cytochrome P450s are classified into several groups depends on their biological functions. The major cytochromes subtypes involved in the drug metabolism are CYP2D6 and CYP3A4. The amount of the drug that is eliminated from the body is predicted by the total clearance.

\section{Results}

3.1. Composition of Tinospora cordifolia: Tinospora cordifolia also known as Guduchi or Amrita is a medicinal plant possessing various therapeutic properties like jaundice, rheumatism, urinary tract infections, dermal diseases, anemia, inflammation, diabetes, etc. The constituents of this plant is known to support the immune system by increasing the body's resistance to infections and also to support the structure, function and levels of white blood cells. The observed pharmacological properties [29, 32, 40-42] of this plant is due to the presence of various constituents like alkaloids, steroids, terpenoids, fatty acid mixtures, polysaccharides, etc. It is also reported that the extract of Tinospora cordifolia possesses broad-spectrum antiviral [43] and protease inhibitors [44]. Based on all the above pharmacological significance of these plant constituents, here in we have tried to investigate the interactions of various constituents with human host receptors for SARS-CoV-2, ACE2 [45-47] and main protease [48-50] by molecular docking [51].

The extract of Tinospora cordifolia consists of constituents that belong to different classes including alkaloids, steroids, terpenoids, lignans, glycosides, polysaccharides, aliphatic compounds, etc. The chemical structure of various significant constituents is shown in

Scheme 1. Structures $\mathbf{1 a}-\mathbf{g}$ belong to alkaloids, $\mathbf{2 a}-\mathbf{b}$ are lignans, $\mathbf{3 a}-\mathbf{e}$ are steroids, $\mathbf{4 a}-$ 
$\mathbf{n}$ are terpenoids and $\mathbf{5 a}-\mathbf{c}$ belong to other categories. Most of these molecules are optically active and their stereochemistry plays a major role in their pharmacological properties.

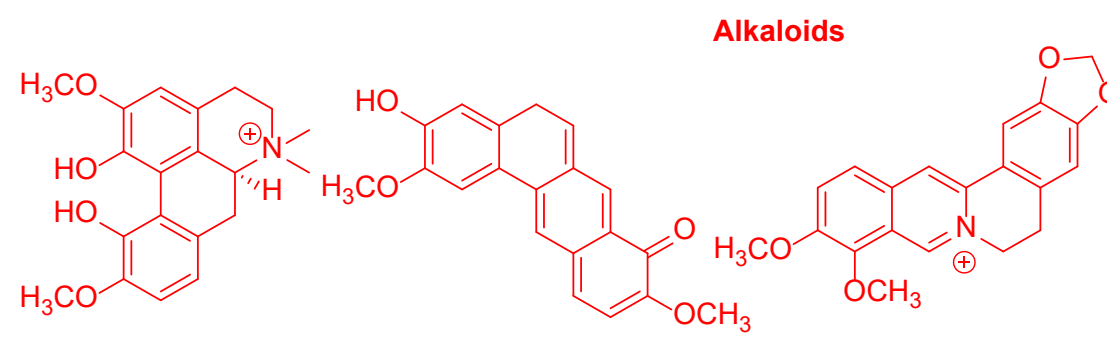

$1 a$<smiles>COc1ccc(C[C@@H]2c3cc(O)ccc3CC[N+]2(C)C)cc1O</smiles>

$1 e$<smiles>CN[C@@H](C)[C@H](O)c1ccccc1</smiles>

$1 f$

$1 \mathrm{~g}$

Lignan<smiles>O=C1OCC(Cc2cccc(O)c2)C1Cc1cccc(O)c1</smiles>

$2 a$<smiles>OCC(Cc1cccc(O)c1)C(CO)Cc1cccc(O)c1</smiles>

2b<smiles>CC(C)CCC[C@H](C)[C@H]1CCC2C3CC=C4C[C@@H](O)CC[C@]4(C)C3CC[C@]21C</smiles>

$3 a$<smiles>CC1(C)CCC2C3CC[C@@H]4Cc5n[nH]cc5C[C@]4(C)C3CC[C@]21C</smiles>

$3 b$<smiles>CC(C)(O)CC[C@@H](O)[C@H](O)[C@@H]1CC[C@]2(O)C3=CC(=O)[C@H]4C[C@H](O)[C@@H](O)C[C@]4(C)[C@H]3CC[C@]12C</smiles>

$3 c$

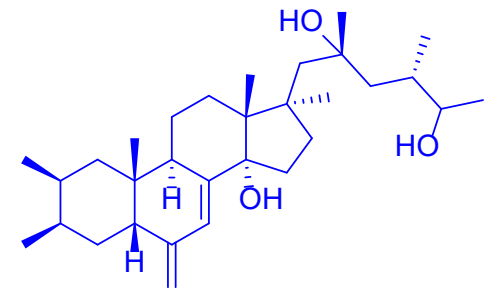

$3 d$<smiles>CC(C)(O)CC[C@@H](O)[C@@](C)(O)[C@H]1CC[C@@]2(O)C3=CC(=O)[C@H]4C[C@H](O)[C@@H](O)C[C@]4(C)[C@H]3CC[C@]12C</smiles> 


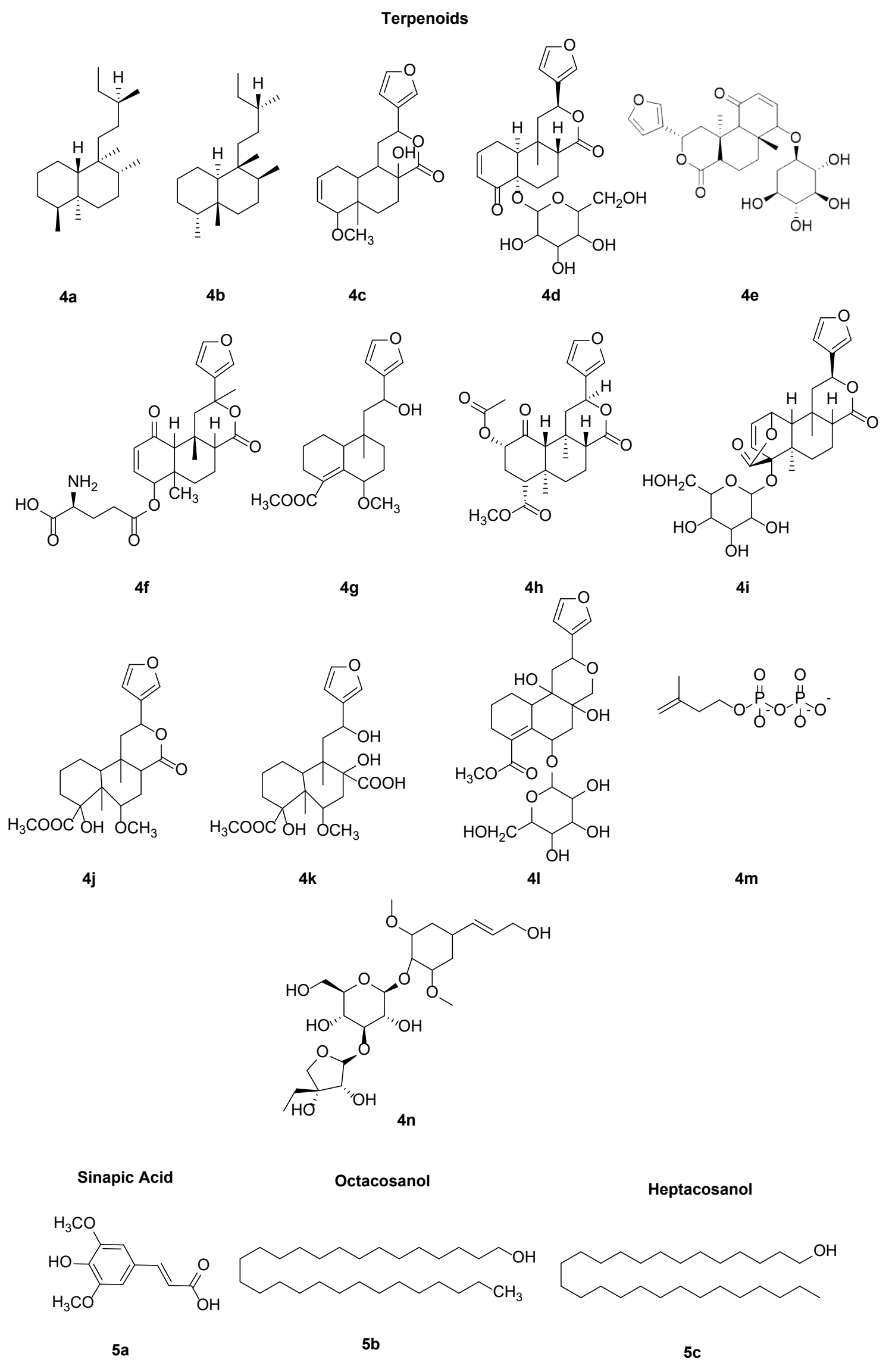

Scheme 1: Chemical constituents of Tinospora cordifolia 
3.2. Docking Simulation. Recently, many natural products $[26,52]$ and refurbished drugs are reported in the literature as possible drug candidates for COVID-19. The broad spectrum therapeutic significance of Tinospora cordifolia has paved way for their investigation as potent inhibitors for SARS-CoV-2. To the best of our knowledge, till date there are no results related to SARS-CoV-2 inhibition through theoretical and experimental studies of compounds in Tinospora cordifolia. Herein we have chosen two targets to study the interaction of the constituents of Tinospora cordifolia: angiotensin converting enzyme (ACE2), an integral membrane glycoprotein, which serves as the human receptor for SARSCoV-2 and the main protease $\left(\mathrm{M}^{\text {pro }}\right)$, which is involves in processing the polyprotein that is translated from viral RNA. With the above two targets we have carried out the molecular docking studies with 31 different constituents of Tinospora cordifolia. The results (Table 1, supporting information) indicate that 1a, 2a, 3a-b and 4a-e exhibit strong interaction while 1b-f, 2b, 3c-d, and 4f-n exhibit moderate inhibition with 2AJF [53] (human ACE2 protein). In order to narrow down, the molecules that contribute significantly towards destabilizing the binding interactions are only considered and are listed in table 1 . The inhibitory effect on 6LU7 [54] (main protease) as evaluated from table 3 indicate that $\mathbf{2 a}$ and $\mathbf{4 a}$ interact strongly while 3a-b and $\mathbf{4 b - e}$ show moderate inhibition. The corresponding interacting residues with 2AJF and 6LU7 are given in table 2 and table 4 respectively.

Table 1: Energy parameters $(\mathrm{kCal} / \mathrm{mol})$ associated with docking interactions of various compounds in Tinospora cordifolia with human ACE2 (PDB id. 2AJF): A, Bindind energy; B, van der Waals \& hydrogen bond energy, C, Electrostatic energy, D, Torsional energy

\begin{tabular}{cccccl}
\hline 2AJF & A & B & C & D & \multicolumn{1}{c}{ Interacting residues } \\
\hline Alkaloids & & & & \multicolumn{1}{l}{$\begin{array}{l}\text { P91, K94, L95, Q98, D206, E208, V209, N210, V212, } \\
P 565, W 566\end{array}$} \\
\hline 1a & -5.5 & -6.63 & -0.95 & 2.09 \\
\hline $1 \mathrm{e}$ & -4.2 & -6.51 & -0.08 & 2.39 & $\begin{array}{l}\text { L91, L95, A99, Q98, E208, V209, N210, L391, L392, } \\
A 396, K 562, E 564, P 565, W 566\end{array}$ \\
\hline
\end{tabular}

Lignans 


\begin{tabular}{|c|c|c|c|c|c|}
\hline $2 b$ & -4.81 & -7.71 & -0.37 & 3.28 & $\begin{array}{l}\text { L91, L95, Q98, A99, E208, V209, N210, V212, K562, } \\
P 565, W 566\end{array}$ \\
\hline \multicolumn{6}{|c|}{ Steroids } \\
\hline $3 a$ & -5.83 & -7.63 & 0.01 & 1.79 & $\begin{array}{l}\text { L95, Q98, Q102, G205, D206, E208, V209, N210, } \\
\text { A396, K562, E564, P565, W566 }\end{array}$ \\
\hline $3 \mathrm{c}$ & -4.84 & -7.53 & -0.29 & 2.98 & $\begin{array}{l}\text { L91, K94, L95, Q98, D206, E208, V209, N210, A396, } \\
\text { E564, P565,W566 }\end{array}$ \\
\hline $3 d$ & -4.62 & -6.8 & -0.21 & 2.39 & $\begin{array}{l}\text { L85, K94, L95, Q98, N194, H195, Y196, V209, N210, } \\
V 212, R 219, P 565\end{array}$ \\
\hline $3 \mathrm{e}$ & -3.83 & -6.55 & -0.56 & 3.28 & L91, L95, Q98, Q102, D206, E208, N210, A396, K562 \\
\hline \multicolumn{6}{|c|}{ Terpenoids } \\
\hline $4 d$ & -5.05 & -7.18 & -0.25 & 2.39 & $\begin{array}{l}\text { L91, L95, Q98, G205, D206, E208, V209, N210, } \\
V 212, A 396, K 562, P 565, W 566\end{array}$ \\
\hline $4 \mathrm{e}$ & -4.88 & -7.09 & 0.12 & 2.09 & $\begin{array}{l}91, \quad L 95, Q 98, Q 102, \quad Y 202, G 205, \text { D206, V209, } \\
A 396, K 562, E 564, \text { P565, W566 }\end{array}$ \\
\hline $4 \mathrm{f}$ & -4.08 & -6.31 & -0.45 & 2.68 & $\begin{array}{l}\text { L95, Q98, G205, D206, E208, V209, A396, K562, } \\
P 565, W 566\end{array}$ \\
\hline $4 \mathrm{~g}$ & -4.03 & -6.09 & -0.03 & 2.09 & $\begin{array}{l}\text { L91, K94, L95, Q98, E208, V209, N210, V212, } \\
\text { E564, P565, W566 }\end{array}$ \\
\hline $4 \mathrm{i}$ & -3.43 & -5.82 & 0.01 & 2.39 & Q86, E87, I88, L91, K94, L95, N210 \\
\hline $4 \mathrm{k}$ & -2.2 & -5.52 & 0.04 & 3.28 & $\begin{array}{l}\text { L91, L95, Q98, G205, D206, E208, V209, A396, } \\
\text { K562, E564, P565, W566 }\end{array}$ \\
\hline 41 & -2.06 & -5.37 & -0.27 & 3.58 & $\begin{array}{l}\text { L95, Q98, A99, Q102, Y202, G205, G206, E208, } \\
\text { A396, K562, E564, P565, W566 }\end{array}$ \\
\hline $4 \mathrm{~m}$ & -1.84 & -4.17 & -0.36 & 2.68 & $\begin{array}{l}\text { L95, D206, V209, N210, A396, K562, P565, } \\
W 566\end{array}$ \\
\hline $4 n$ & 0.98 & -4.12 & -0.57 & 5.67 & $\begin{array}{l}\text { Q102, Y196, Y202, G205, D206, N394, N397, } \\
\text { G395, E398, K562 }\end{array}$ \\
\hline \multicolumn{6}{|c|}{ Others } \\
\hline $5 b$ & -1.04 & -9.03 & -0.07 & 8.05 & $\begin{array}{l}\text { L91, K94, L95, Q98, A99, D206, E208, V209, } \\
\text { N210, A396, K562, E564, P565, W566 }\end{array}$ \\
\hline $5 c$ & -0.59 & -8.3 & -0.04 & 7.76 & $\begin{array}{l}\text { L91, K94, L95, Q98, D206, E208, V209, N210, } \\
\text { K562, E564, P565 }\end{array}$ \\
\hline
\end{tabular}

The interacting resides from the binding pocket of $2 \mathrm{AJF}$ with various constituents are given in (Table 2, Supporting Information). The dominantly interacting compounds with 2AJF are depicted in figure 1.

$1 a$
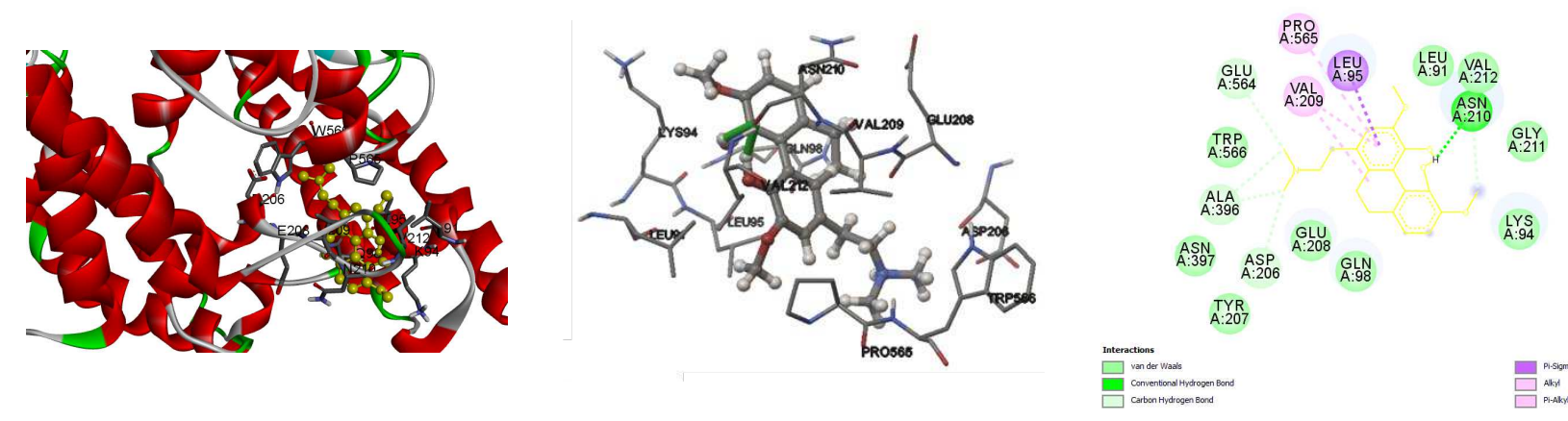
2a
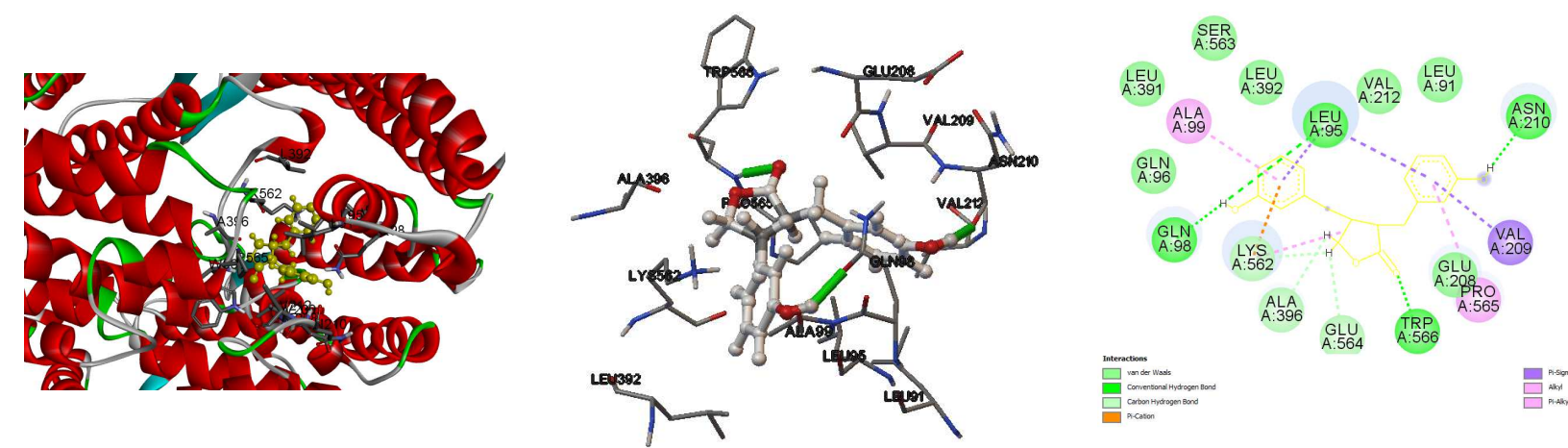

$3 a$
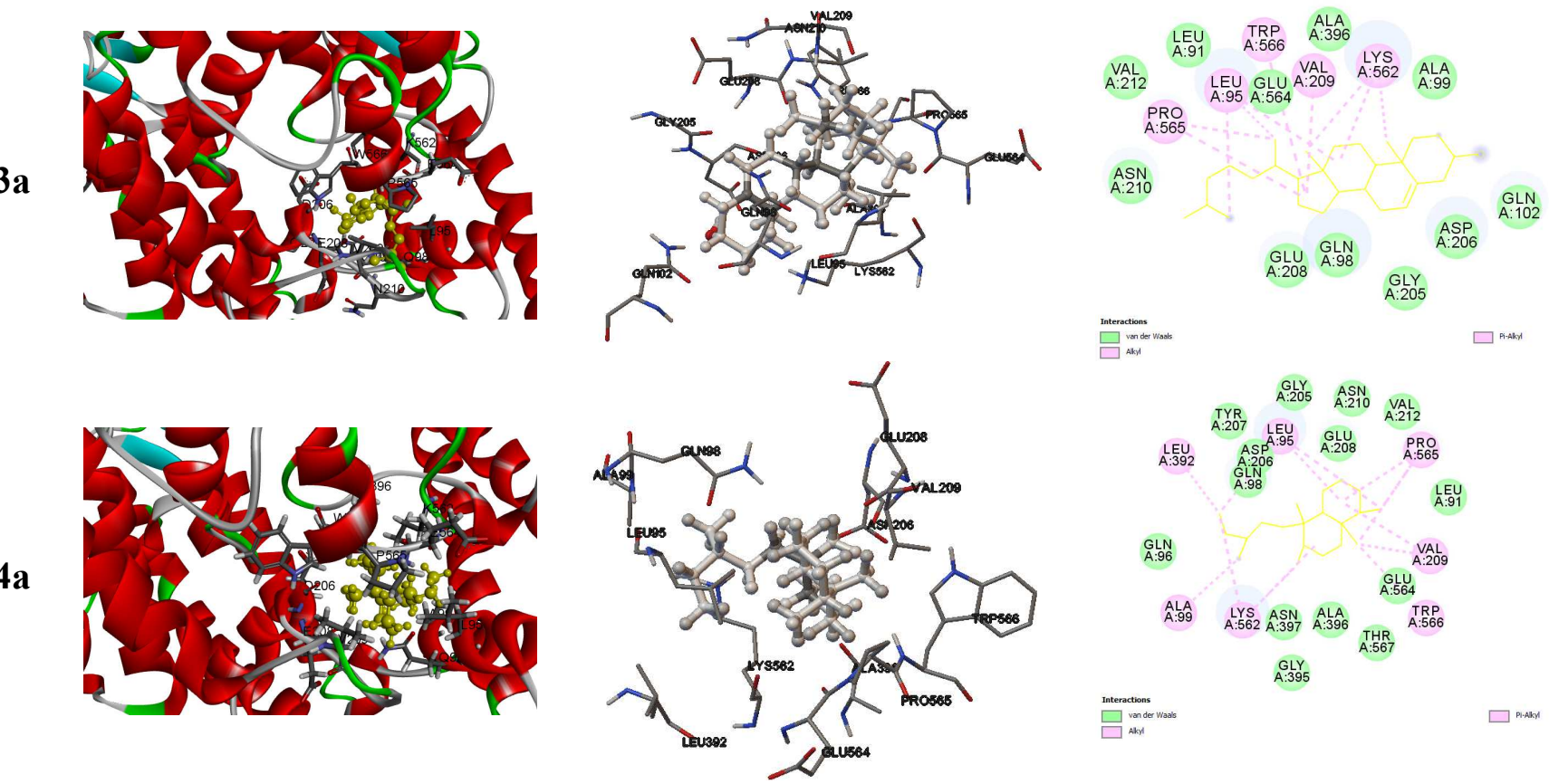

Figure 1. Representative docked conformation of various constituents of Tinospora cordifolia with 2AJF.

The interaction of various classes of compounds from the extract of Tinospora cordifolia was investigated with the main protease (6LU7) of SARS-CoV-2 and the results are given Table 2 along with the interacting residues (Table $3 \& 4$ Supporting Information). Unlike the interactions with human ACE2, compounds $\mathbf{3 b}$ and $\mathbf{4 f}$ were found to exhibit strong interaction while moderate interactions were observed in the cases of $\mathbf{3 a}, \mathbf{3 d}, \mathbf{4 a}, \mathbf{4 b}, \mathbf{4} \mathbf{e}$ and 4h. No significant interactions were observed with alkaloid class of compounds as such. The interacting residues are tabulated in (Table 4, Supporting Information) and the significant inhibitory interactions from the selected compounds are depicted in figure 2. 
Table 2: Energy parameters $(\mathrm{kCal} / \mathrm{mol})$ associated with docking interactions of various compounds in Tinospora cordifolia with human M $\mathrm{M}^{\text {pro }}$ (PDB id. 6LU7): A, Bindind energy; B, van der Waals \& hydrogen bond energy, C, Electrostatic energy, D, Torsional energy.

\begin{tabular}{cccccl}
\hline 6LU7 & $\mathbf{A}$ & $\mathbf{B}$ & $\mathbf{C}$ & $\mathbf{D}$ & \multicolumn{1}{c}{ Interacting residues } \\
\hline $3 \mathrm{~b}$ & -5.05 & -5 & -0.05 & 0 & $T 26, L 27, H 41, G 143, M 165, E 166, Q 189$ \\
$\mathrm{Hf}$ & -5.09 & -6.22 & -1.55 & 2.68 & $\begin{array}{l}T 26, L 27, H 41, M 49, F 140, L 141, N 142, G 143, S 144, \\
C 145, H 163, H 164, M 165, E 166\end{array}$ \\
\hline
\end{tabular}
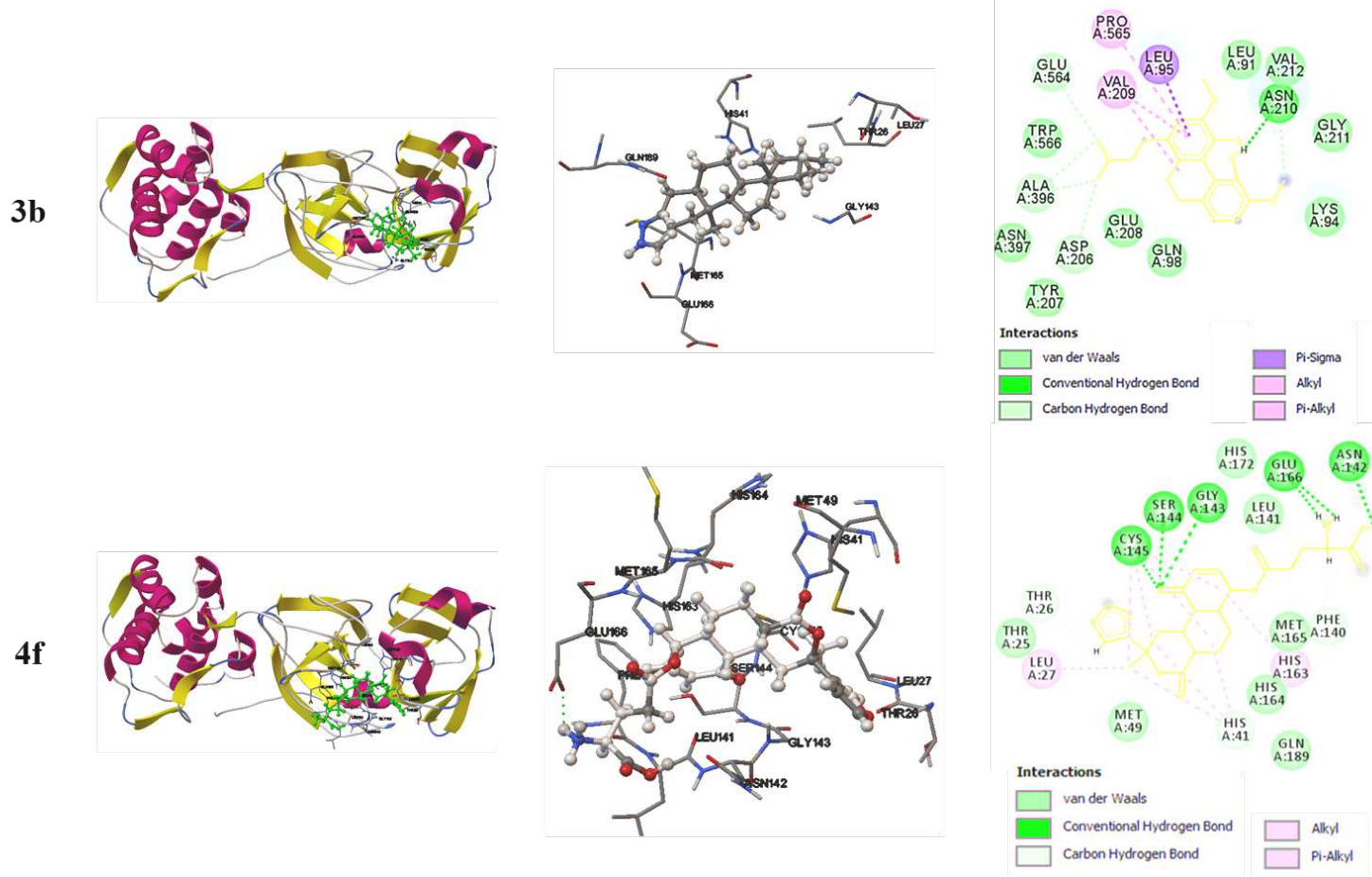

Figure 2. Docked conformation of various constituents of Tinospora cordifolia with 6LU7. 


\subsection{Absorption, Distribution, Metabolism, Excretion and Toxicity Studies [55-57]}

3.3.1. Prediction of ADMET properties of Alkaloids. The pharmacokinetic (PK) parameters play important role in drug discovery process. [58] The predicted ADME/T properties are given in (Table 5 supporting information). It could be observed that compounds $\mathbf{1 a}, \mathbf{1} \mathbf{c}$ and $\mathbf{1 d}$ are poorly absorbed due to their high polar nature, though they have high potential to penetrate the cell membrane. The absorption properties of the alkaloids are listed in ESI table 5. The listed alkaloids show high distribution, expect for $\mathbf{1 g}$. All the listed alkaloids possess the ability to penetrate through the CNS except 1c. All alkaloids can be easily cleared from the system except 1b. The toxicology prediction shows that all alkaloids exhibit hepatotoxicity except 1a, 1e and $\mathbf{1 f}$ while 1e exhibits cardiotoxicity.

3.3.2. Prediction of ADMET properties of Lignans and Steroids. The predicted ADME/T properties of lignans and steroids are given in Table 6 (supporting information). The results indicate that lignans possess better absorption ability than steroids. Among the lignans and steroids only $\mathbf{3 b}$ shows high distribution potential. The compounds 3a and $\mathbf{3 d}$ can easily penetrate through the CNS. 2a, $2 \mathbf{b}$ and $\mathbf{3 d}$ show moderate levels for excretion. The compounds 2a, 2b, 3a, 3b exhibit cardiotoxicity whereas hepatotoxicity is observed only for $\mathbf{3 b}$ and $\mathbf{3 d}$.

3.3.3. Prediction of ADMET properties of Terpinoids. The predicted ADME/T properties of terpenoids are given in Table 7 (supporting information). The results indicate that all terpenoids except $\mathbf{4 a}, \mathbf{4 b}$ and $\mathbf{4 n}$ are highly polar and show poor absorption. The compounds $4 \mathbf{a}$ and $\mathbf{4 b}$ possess the ability to cross blood brain barrier while all terpenoids exhibit similar tendency to permeate CNS. Except $\mathbf{3 f}$ all the terpenoids can be easily excreted from the body. $\mathbf{4 g}, \mathbf{4 j}$ and $\mathbf{4 k}$ show hepatotoxicity. 
3.3.4. Prediction of ADMET properties of Others. The predicted ADME/T properties of other constituents are given in Table 8 (supporting information). Compound 5a exhibits very good absorption and membrane permeation. $\mathbf{5 b}$ and $\mathbf{5 c}$ possess the ability to cross the BBB easily while compound $\mathbf{5 a}$ can penetrate the CNS. 5a induces hepatotoxicity while compounds $\mathbf{5 b}$ and 5c are cardiotoxic. The predicted ADME/T properties of selected compounds are listed in table

3.

Table 3. Predicted ADME/T properties

\begin{tabular}{ccccccc}
\hline \multirow{2}{*}{ Compounds } & $\begin{array}{c}\text { Polar Surface } \\
\text { Area }\end{array}$ & LogP & $\begin{array}{c}\text { BBB } \\
\text { permeability }\end{array}$ & $\begin{array}{c}\text { CNS } \\
\text { permeability }\end{array}$ & $\begin{array}{c}\text { Total } \\
\text { Clearance }\end{array}$ & Hepatotoxicity \\
\hline 1e & 139.63 & 3.0607 & -0.221 & -2.403 & 0.743 & No \\
3a & 174.309 & 7.3887 & 0.777 & -1.746 & 0.589 & No \\
$4 \mathrm{~b}$ & 127.66 & 6.6914 & 0.853 & -1.399 & 0.986 & No \\
$4 \mathrm{n}$ & 206.31 & -0.559 & -1.742 & -4.092 & 1.576 & No \\
$5 \mathrm{~b}$ & 185.387 & 10.1412 & 1.029 & -1.066 & 2.152 & No \\
$5 \mathrm{c}$ & 179.022 & 9.7511 & 1.004 & -1.054 & 2.13 & No \\
\hline
\end{tabular}

\section{Discussions}

Among the selected candidates listed in Table 1, it could be observed that the major destabilizing contribution is from the torsional energy arising from the presence of freely rotating single bonds. $1 \mathrm{~g}$ was found to have very poor interaction among the alkaloids. Similarly in the case of lignans and steroids $\mathbf{2 a}$ and 3a-b have comparatively stronger affinity for the considered active site than $2 \mathrm{~b}$ and $\mathbf{3 c - d}$ respectively. In case of terpenoids, $\mathbf{4 a - d}$ bind strongly to the active site than the moderately binding 4e-g. It could be observed from Table 2 and Table 1 (supporting information) that the major interacting residues are non-polar in nature. In the case of $\mathbf{4 d}$, the stabilization caused by non-polar interactions is nullified by the high torsional energy of the molecule. Though there is a negligible difference in the intermolecular energy for all the above preferred molecules, the moderately binding ones have high torsional energy, which reduces 
their target interaction, while the imparted stability has its major contribution from hydrogen bond interactions and van der waals interactions. $\mathbf{5 b}$-c , bind weakly to the target $2 \mathrm{AJF}$, as the intermolecular stabilizing energy is neutralized by the high torsional energies. In this case, the stabilizing interactions have its contribution from polar and acidic amino acids along with nonpolar interactions. In compound $\mathbf{4 f}$, though the torsional energy is very high, the stabilizing effect is observed from the low internal energy of the molecule.

Though the results of molecular docking have revealed compounds 1a 1e, 2a-c and 3a-d as potential COVID-19 candidates, the properties predicted from the absorption, distribution, metabolism, excretion and toxicology (ADMET) studies have further narrowed down the list of candidates to 6 compounds (1e, $\mathbf{3 a}, \mathbf{4 b}, \mathbf{4 n}, \mathbf{5 b}$ and $\mathbf{5 c})$.

\section{Conclusions}

The docking results indicate that among all the constituent compounds 1a, 1e, 2a-c and 3a-d possess the ability to interact strongly with human ACE2 protein and $\mathbf{3 b}$ and $\mathbf{4} \mathbf{f}$ with the main protease of SARS-CoV-2. It is believed that such strong interaction with human receptor for SARS-CoV-2 could prevent the entry of the virus and thus could act as a prophylactic for COVID-19. From the overall ADMET properties, it could be concluded that compounds 1a, 1e, $\mathbf{2 a}, \mathbf{2 b}, \mathbf{4 a}, \mathbf{4 g}$ and $\mathbf{5 a}$ as potential drug candidates for COVID-19. Overall observation from combined results of docking analysis and ADMET properties revealed compounds $\mathbf{1 e}, \mathbf{3 a}, \mathbf{4 b}$, 4n, $5 \mathbf{b}$ and $\mathbf{5 c}$ could be potential drug candidates out of 31 constituents of the extract from Tinospora cordifolia. The druggable potential of the above six constituents can be tuned by engineering the molecules with less torsional energies and by lowering their cardiotoxicity.

\section{FUNDING}

None. 


\section{CONFLICT OF INTEREST}

The authors declare no competing financial interest.

\section{Acknowledgements}

The authors thank the Chancellor and Vice Chancellor of Vellore Institute of Technology for providing opportunity to carry out this study.

The authors declare no competing financial interest.

\section{SUPPLEMENTARY MATERIAL}

Supplementary material is available on the publisher's web site along with the published article.

\section{References}

[1] Saul, S., Einav, S. Old Drugs for a New Virus: Repurposed Approaches for Combating COVID-19. ACS Infec. Dis. 2020. DOI: 10.1021/acsinfecdis.0c00343

[2] Ciotti, M., Angeletti, S., Minieri, M., Giovannetti, M., Benvenuto, D., Pascarella, S., et al. COVID-19 Outbreak: An Overview. Chemotherapy, 2019, 64, 215-23.

[3] Patil, A.M., Gothert, J.R., Khairnar, V. Emergence, Transmission, and Potential Therapeutic Targets for the COVID-19 Pandemic Associated with the SARS-CoV-2. Cell. Physiol. Biochem. 2020, 54, 767-90.

[4] Ashour, H.M., Elkhatib, W.F., Rahman, M.M., Elshabrawy, H.A. Insights into the Recent 2019 Novel Coronavirus (SARS-CoV-2) in Light of Past Human Coronavirus Outbreaks. Pathogens. 2020, 9.

[5] Yan, Y., Shin, W.I., Pang, Y.X., Meng, Y., Lai, J., You, C., et al. The First 75 Days of Novel Coronavirus (SARS-CoV-2) Outbreak: Recent Advances, Prevention, and Treatment. Int. J. Env. Res. Pub. He. 2020, 17 
[6] Muldoon, K.M., Fowler, K.B., Pesch, M.H., Schleiss, M.R. SARS-CoV-2: Is it the newest spark in the TORCH? J. Clin. Virol. 2020, 127, 104372

[7] Abd El-Aziz, T.M., Stockand, J.D. Recent progress and challenges in drug development against COVID-19 coronavirus (SARS-CoV-2) - an update on the status. I J. Mol. Epidemiol. Evol. Gen. Infec. Dis. 2020, 83, 104327

[8] Halaji, M., Farahani, A., Ranjbar, R., Heiat, M., Dehkordi, F.S. Emerging coronaviruses: first SARS, second MERS and third SARS-CoV-2: epidemiological updates of COVID-19. Le infezioni in medicina. 2020, 28, 6-17.

[9] Singh, A., Singh, R.S., Sarma, P., Batra, G., Joshi, R., Kaur, H., et al. A Comprehensive Review of Animal Models for Coronaviruses: SARS-CoV-2, SARS-CoV, and MERS-CoV. Virol. Sinica. 2020, 35, 290-304.

[10] Hasoksuz, M., Kilic, S., Sarac, F. Coronaviruses and SARS-COV-2. Turk. J. Med. Sci. 2020, 50, 549-56.

[11] Ludwig, S., Zarbock, A. Coronaviruses and SARS-CoV-2: A Brief Overview. Anesth. Analg. 2020, 131, 93-6.

[12] Sheahan, T.P., Sims, A.C., Zhou, S., Graham, R.L., Pruijssers, A.J., Agostini, M.L., et al. An orally bioavailable broad-spectrum antiviral inhibits SARS-CoV-2 in human airway epithelial cell cultures and multiple coronaviruses in mice. Sci. Transl. Med. 2020, 12.

[13] Tulgar, S., Ahiskalioglu, A., Kok, A., Thomas, D.T. Possible Old Drugs for Repositioning in COVID-19 Treatment: Combating Cytokine Storms from Haloperidol to Anti-interleukin Agents. Turk. J. Anaesthesiol. Reanim. 2020, 48, 256-7.

[14] Bradley, B.T., Bryan, A. Emerging respiratory infections: The infectious disease pathology of SARS, MERS, pandemic influenza, and Legionella. Semin. Diagn. Pathol. 2019, 36, 152-9. 
[15] Song, Z., Xu, Y., Bao, L., Zhang, L., Yu, P., Qu, Y., et al. From SARS to MERS, Thrusting Coronaviruses into the Spotlight. Viruses. 2019, 11.

[16] Bein, B., Bachmann, M., Huggett, S., Wegermann, P. [SARS CoV-2/COVID-19: EvidenceBased Recommendation on Diagnosis and Therapy]. Anasthesiologie, Intensivmedizin, Notfallmedizin, Schmerztherapie : AINS. 2020, 55, 257-65.

[17] Lobo-Galo, N., Terrazas-Lopez, M., Martinez-Martinez, A., Diaz-Sanchez, A.G. FDAapproved thiol-reacting drugs that potentially bind into the SARS-CoV-2 main protease, essential for viral replication. J. Biomol. Struc. Dyn. 2020, 1-9.

[18] Klimke, A., Hefner, G., Will, B., Voss, U. Hydroxychloroquine as an aerosol might markedly reduce and even prevent severe clinical symptoms after SARS-CoV-2 infection. Med. Hypothe. 2020, 142, 109783.

[19] Kim, S., Choi, S., Ko, Y., Ki, M., Jung, E. Risk estimation of the SARS-CoV-2 acute respiratory disease outbreak outside China. Theor. Biol. Med. Model. 2020, 17, 9.

[20] Wang, Y., An, G., Becker, A., Cockrell, C., Collier, N., Craig, M., et al. Rapid communitydriven development of a SARS-CoV-2 tissue simulator. bioRxiv : the preprint server for biology. 2020.

[21] Rensi, S., Altman, R.B., Liu, T., Lo, Y.C., McInnes, G., Derry, A., et al. Homology Modeling of TMPRSS2 Yields Candidate Drugs That May Inhibit Entry of SARS-CoV-2 into Human Cells. ChemRxiv : the preprint server for chemistry. 2020.

[22] Lisi, L., Lacal, P.M., Barbaccia, M.L., Graziani, G. Approaching coronavirus disease 2019: Mechanisms of action of repurposed drugs with potential activity against SARS-CoV-2. Biochem. Pharmacol. 2020, 180, 114169. 
[23] Idrees, M., Khan, S., Memon, N.H., Zhang, Z. Effect of the Phytochemical Agents Against the SARS-CoV and Selected Some of them for Application to COVID-19: A Mini-Review. Curr. Pharma. Biotech. 2020.

[24] Jahan, I., Onay, A. Potentials of plant-based substance to inhabit and probable cure for the COVID-19. Turk. J. Biol. 2020, 44, 228-41.

[25] Rosales-Mendoza, S. Will plant-made biopharmaceuticals play a role in the fight against COVID-19? Expert Opin. Biol. Ther. 2020, 20, 545-8.

[26] Sharma, A., Tiwari, V., Sowdhamini, R. Computational search for potential COVID-19 drugs from FDAapproved drugs and small molecules of natural origin identifies several antivirals and plant products. J. Biosci. 2020, 45.

[27] Priya, R., Sujatha, V. AYUSH for COVID-19: Science or Superstition? Ind. J. Pub. He. 2020, 64, S105-S7.

[28] Alsuhaibani, S., Khan, M.A. Immune-Stimulatory and Therapeutic Activity of Tinospora cordifolia: Double-Edged Sword against Salmonellosis. J. Immunol. Res. 2017, 2017, 1787803.

[29] Dhama, K., Sachan, S., Khandia, R., Munjal, A., Iqbal, H.M.N., Latheef, S.K., et al. Medicinal and Beneficial Health Applications of Tinospora cordifolia (Guduchi): A Miraculous Herb Countering Various Diseases/Disorders and its Immunomodulatory Effects. Recent patents on endocrine, metabolic \& immune drug discovery. 2017, 10, 96-111.

[30] Kaushik, A., Husain, A., Awasthi, H., Singh, D.P., Khan, R., Mani, D. Antioxidant and Hepatoprotective Potential of Swaras and Hima Extracts of Tinospora cordifolia and Boerhavia diffusa in Swiss albino Mice. Pharmacogn. Mag. 2017, 13, S658-S62. 
[31] Kalikar, M.V., Thawani, V.R., Varadpande, U.K., Sontakke, S.D., Singh, R.P., Khiyani, R.K. Immunomodulatory effect of Tinospora cordifolia extract in human immuno-deficiency virus positive patients. Ind. J. Pharmacol. 2008, 40, 107-10.

[32] Sharma, P., Dwivedee, B.P., Bisht, D., Dash, A.K., Kumar, D. The chemical constituents and diverse pharmacological importance of Tinospora cordifolia. Heliyon. 2019, 5, e02437.

[33] Wang, J. Fast Identification of Possible Drug Treatment of Coronavirus Disease-19 (COVID-19) through Computational Drug Repurposing Study. J. Chem. Inform. Model. 2020, $60,3277-86$.

[34] Zhang, Y., Zeng, T., Chen, L., Ding, S., Huang, T., Cai, Y.D. Identification of COVID-19 Infection-Related Human Genes Based on a Random Walk Model in a Virus-Human Protein Interaction Network. BioMed Res. Intern. 2020, 2020, 4256301.

[35] Peng, Y.D., Zhou, L.S., Chen, L.L., Ma, L., Zhao, Y., Zhang, W.W., et al. Ferroceneisocoumarin conjugated molecules: synthesis, structural characterization, electronic properties, and DFT-TDDFT computational study. Dalton Tranns. 2015, 44, 14465-74.

[36] Panchangam, R.L., Manickam, V., Chanda, K. Assembly of Fully Substituted 2H-Indazoles Catalyzed by $\mathrm{Cu} 2 \mathrm{O}$ Rhombic Dodecahedra and Evaluation of Anticancer Activity. ChemMedChem, 2019, 14, 262-271.

[37] Padmaja, R.D., Balamurali, M.M., Chanda, K. One-Pot, Telescopic Approach for the $\begin{array}{llll}\text { Chemoselective } & \text { Synthesis } & \text { of }\end{array}$ Benzo[e]pyrido/pyrazino/pyridazino[1,2-b][1,2,4]thiadiazine dioxides and Their Significance in Biological Systems. J. Org. Chem. 2019, 84, 11382-11390.

[38] Rao, R.N., Chanda, K. An assessment study of known pyrazolopyrimidines: chemical methodology and cellular activity. Bioorg. Chem. 2020, 99, 103801. 
[39] Rao, R.N., Panchangam, R.L., Manickam, V., Balamurali, M.M., Chanda, K. Synthesis and Antitumor Activity Evaluation of Cyclometalated 2H-Indazole Ruthenium (II) and Iridium (III) Complexes. ChemPlusChem, 2020, 85, 1800-1812.

[40] Singh, D., Chaudhuri, P.K. Chemistry and Pharmacology of Tinospora cordifolia. Nat. Prod. Commun. 2017, 12, 299-308.

[41] Stanca, M.H., Nagy, A., Tosa, M., Vlad, L. [Hepatoprotective effects of orally administered melatonin and tinospora cordifolia in experimental jaundice]. Chirurgia. 2011, 106, 205-10.

[42] Upadhyay, A.K., Kumar, K., Kumar, A., Mishra, H.S. Tinospora cordifolia (Willd.) Hook. f. and Thoms. (Guduchi) - validation of the Ayurvedic pharmacology through experimental and clinical studies. Int. J. Ayurved. Res. 2010, 1, 112-21.

[43] Chowdhury, P. In silico investigation of phytoconstituents from Indian medicinal herb 'Tinospora cordifolia (giloy)' against SARS-CoV-2 (COVID-19) by molecular dynamics approach. J. Biomol. Struc. Dyn. 2020, 1-18.

[44] Gala, V.C., John, N.R., Bhagwat, A.M., Datar, A.G., Kharkar, P.S., Desai, K.B. Attenuation of quorum sensing-regulated behaviour by Tinospora cordifolia extract \& identification of its active constituents. Ind. J. Med. Res. 2016, 144, 92-103.

[45] Armijos-Jaramillo, V., Yeager, J., Muslin, C., Perez-Castillo, Y. SARS-CoV-2, an evolutionary perspective of interaction with human ACE2 reveals undiscovered amino acids necessary for complex stability. Evol. Appl. 2020.

[46] Liu, H., Gai, S., Wang, X., Zeng, J., Sun, C., Zhao, Y., et al. Single-cell analysis of SARSCoV-2 receptor ACE2 and spike protein priming expression of proteases in the human heart. Cardiovasc. Res. 2020, 116, 1733-41. 
[47] Lu, J., Sun, P.D. High affinity binding of SARS-CoV-2 spike protein enhances ACE2 carboxypeptidase activity. bioRxiv : the preprint server for biology. 2020.

[48] Ibrahim, M.A.A., Abdeljawaad, K.A.A., Abdelrahman, A.H.M., Hegazy, M.F. Natural-like products as potential SARS-CoV-2 M(pro) inhibitors: in-silico drug discovery. J. Biomol. Struc. Dyn. 2020, 1-13.

[49] Lokhande, K.B., Doiphode, S., Vyas, R., Swamy, K.V. Molecular docking and simulation studies on SARS-CoV-2 M(pro) reveals Mitoxantrone, Leucovorin, Birinapant, and Dynasore as potent drugs against COVID-19. J. Biomol. Struc. Dyn. 2020, 1-12.

[50] Sacco, M.D., Ma, C., Lagarias, P., Gao, A., Townsend, J.A., Meng, X., et al. Structure and inhibition of the SARS-CoV-2 main protease reveals strategy for developing dual inhibitors against M(pro) and cathepsin L. bioRxiv : the preprint server for biology. 2020.

[51] Morris, G.M., Huey, R., Lindstrom, W., Sanner, M.F., Belew, R.K., Goodsell, D.S., et al. AutoDock4 and AutoDockTools4: Automated docking with selective receptor flexibility. $J$. Comput. Chem. 2009, 30, 2785-91.

[52] Williamson, G., Kerimi, A. Testing of natural products in clinical trials targeting the SARSCoV-2 (Covid-19) viral spike protein-angiotensin converting enzyme-2 (ACE2) interaction. Biochem. Pharmacol. 2020, 178, 114123.

[53] Li, F., Li, W., Farzan, M., Harrison, S.C. Structure of SARS coronavirus spike receptorbinding domain complexed with receptor. Science 2005, 309, 1864-8.

[54] Jin, Z., Du, X., Xu, Y., Deng, Y., Liu, M., Zhao, Y., Zhang, B., Li, X., Zhang, L., Peng, C., Duan, Y., Yu, J., Wang, L., Yang, K., Liu, F., Jiang, R., Yang, X., You, T., Liu, X., Yang, X., Bai, F., Liu, H., Liu, X., Guddat, L.W., Xu, W., Xiao, G., Qin, C., Shi, Z., Jiang, H., Rao, Z., 
Yang, H. Structure of Mprofrom SARS-CoV-2 and discovery of its inhibitors. Nature 2020, 582, 289-93.

[55] Eddershaw, P.J., Beresford, A.P., Bayliss, M.K. ADME/PK as part of a rational approach to drug discovery. Drug Discov. Today. 2000, 5, 409-14.

[56] Ekins, S., Waller, C.L., Swaan, P.W., Cruciani, G., Wrighton, S.A., Wikel, J.H. Progress in predicting human ADME parameters in silico. J. Pharmacol. Tox. Met. 2000, 44, 251-72.

[57] Thompson, T.N. Early ADME in support of drug discovery: the role of metabolic stability studies. Curr. Drug. Metabol. 2000, 1, 215-41.

[58] Ortega, S.S., Cara, L.C., Salvador, M.K. In silico pharmacology for a multidisciplinary drug discovery process. Drug Metabol. Drug Interact. 2012, 27, 199-207.

[59] Kollman, U.C.S.P.A. An approach to computing electrostatic charges for molecules. $J$. Comput. Chem. 1984, 5, 129-45.

[60] Han, Y., Zhang, J., Hu, C.Q., Zhang, X., Ma, B., Zhang, P. In silico ADME and Toxicity Prediction of Ceftazidime and Its Impurities. Front. Pharmacol. 2019, 10, 434.

[61] Pires, D.E., Blundell, T.L., Ascher, D.B. pkCSM: Predicting Small-Molecule Pharmacokinetic and Toxicity Properties Using Graph-Based Signatures. J. Med. Chem. 2015, $58,4066-4072$.

[62] Norinder, U., Bergstrom, C.A. Prediction of ADMET Properties. ChemMedChem, 2006, 1, 920-37.

[63] Sanders, J.M., Beshore, D.C., Culberson, J.C., Fells, J.I., Imbriglio, J.E., Gunaydin, H., et al. Informing the Selection of Screening Hit Series with in Silico Absorption, Distribution, Metabolism, Excretion, and Toxicity Profiles. J. Med. Chem. 2017, 60, 6771-6780. 
Figures
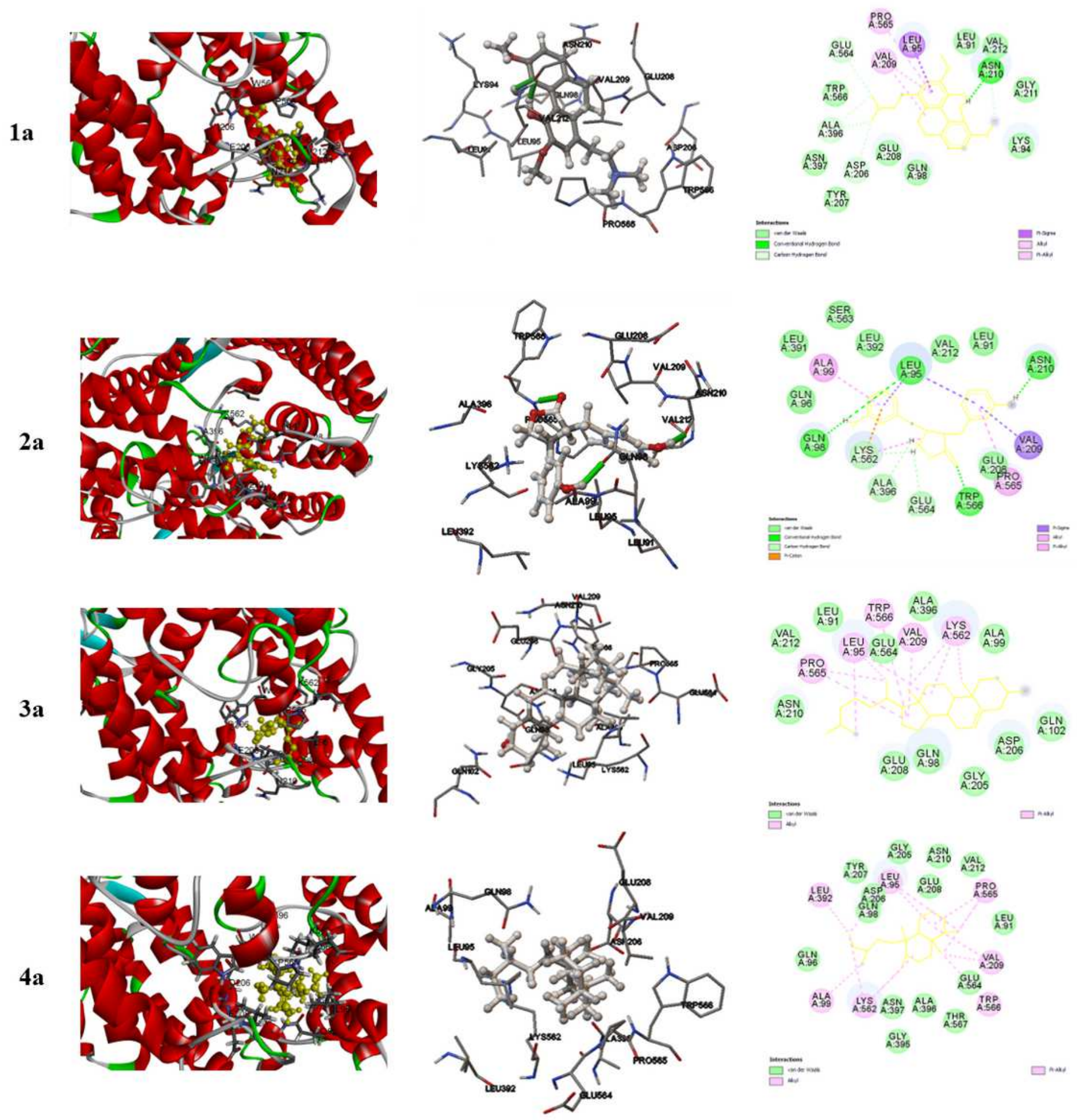

Figure 1

Representative docked conformation of various constituents of Tinospora cordifolia with 2AJF. 

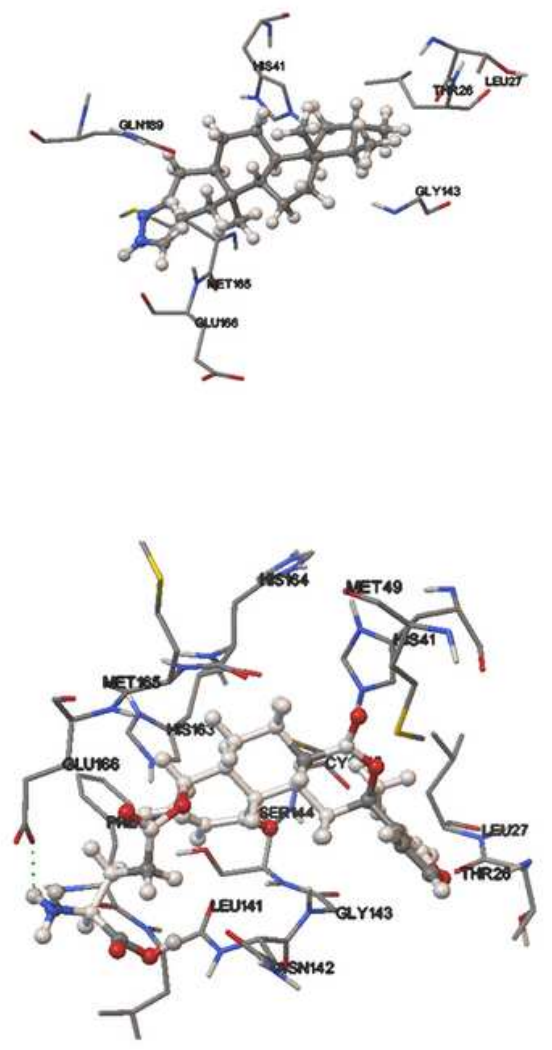

$3 \mathbf{b}$
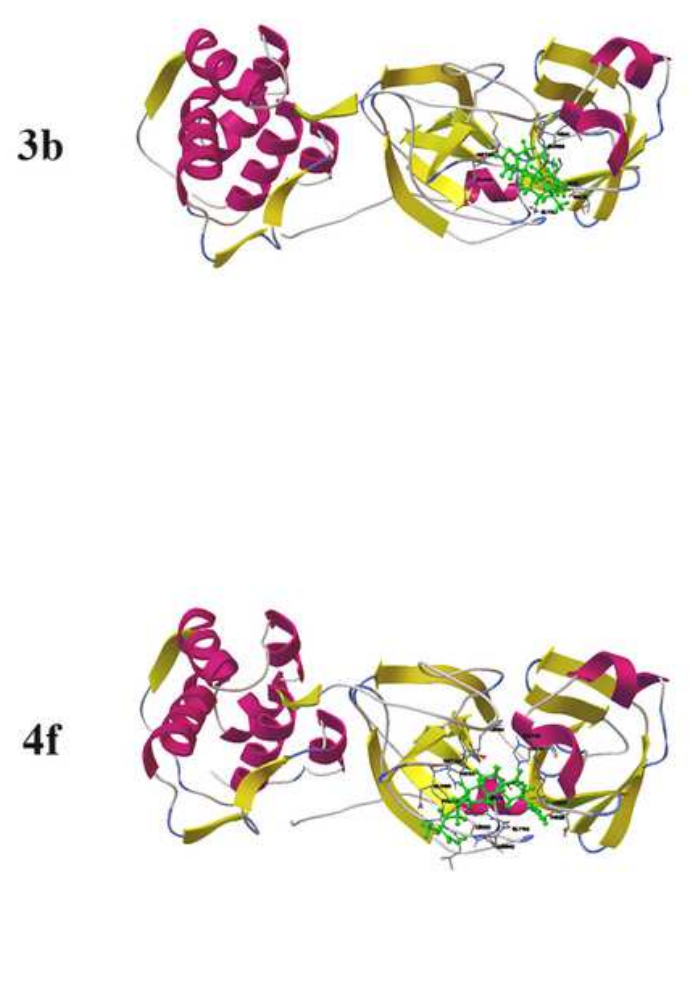

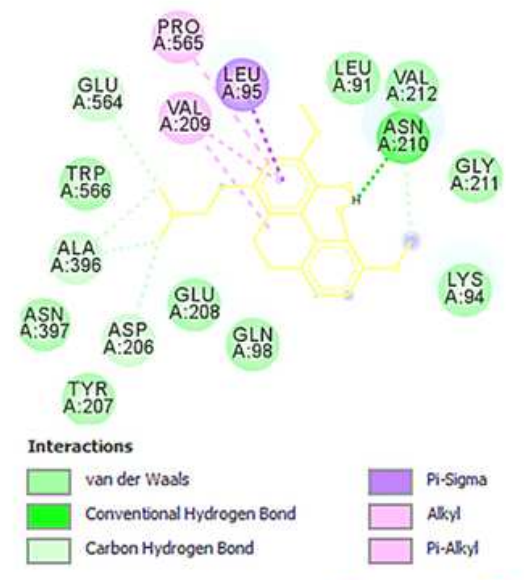

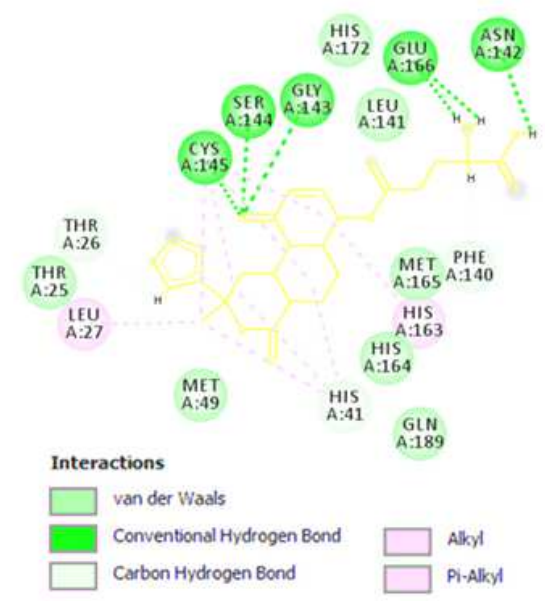

\section{Figure 2}

Docked conformation of various constituents of Tinospora cordifolia with 6LU7.

\section{Supplementary Files}

This is a list of supplementary files associated with this preprint. Click to download.

- SupportingInformation.docx 